\title{
Antifungal Activity of Fumaric Acid in Mice Infected with Candida albicans
}

\author{
Mitsutaro AKAO* and Keiko Kuroda \\ Research Center for Pathogenic Fungi and Microbial Toxicoses, Chiba University, 1-8-1 Inohana, Chiba 280, Japan. Received June 13, 1991
}

\begin{abstract}
An examination was made on the effect of fumaric acid on an experimental systemic candidiasis. Male ICR mice were innoculated into the tail veins with $10^{6}$ yeast cells of Candida albicans and treated with daily intraperitoneal injections of fumaric acid at the dose of $40 \mathrm{mg} / \mathrm{kg} / \mathrm{d}$. The results indicated that the administration of fumaric acid was effective in prolonging the survival of animals after the fungal challenge and prevented one-fifth of the treated animals from dying of candidiasis.
\end{abstract}

Keywords fumaric acid; Candida albicans; systemic mycosis; antifungal activity

\section{Introduction}

In our pharmacological studies on the extract of Capsella burse-pastoris (Cruciferae), fumaric acid (FA) was isolated and identified as the component of the herb responsible for inhibiting the growth of subcutaneously transplanted Ehrlich tumors in mice and gastric ulceration in rats. ${ }^{1,2)}$ Thereafter, we found that FA reduced the toxic symptoms in mice and rats injected with mitomycin $\mathrm{C}$ or aflatoxin $\mathrm{B}_{1}{ }^{3-5)}$ and that FA suppressed hepatocarcinogenesis in rats fed 3'-methyl-4-(dimethylamino)azobenzene or thioacetamide $^{6,7)}$ or hepatocarcinogenesis in mice fed thioacetamide. ${ }^{8)}$ The present study indicates that FA has a different chemotherapeutic activity, i.e., an antifungal activity in a model system of candidiasis, one of the most frequent human mycoses.

\section{Materials and Methods}

Animals used were male ICR mice weighing approximately $20 \mathrm{~g}$. They were supplied from Clea Japan Inc., Tokyo, housed 5 to each cage, and maintained on a basal diet CE-2 (Clea Japan Inc.) and water ad libitum. The strain of Candida albicans used was ATCC 48130. Suspensions of living yeasts were prepared from fresh cultures grown $2 \mathrm{~d}$ on Sabrouraud dextrose agar slants at $37^{\circ} \mathrm{C}$. Yeast cells were harvested from the slants with a platinum loop, washed with saline $(0.9 \% \mathrm{NaCl}$ solution), and resuspended in saline. Then, $5 \times 10^{6}$ per $\mathrm{ml}$ cell suspension was prepared by using a Thoma's hemocytometer. Each mouse was innoculated into the tail vein with $0.2 \mathrm{ml}$ of cell suspension. On the following day, mice were divided into two groups. One group received daily intraperitoneal injections of $40 \mathrm{mg} / \mathrm{kg}$ of FA (Nakarai Chemicals Ltd., Kyoto) dissolved in saline $(5 \mathrm{mg} / \mathrm{ml})$ and the other (control) group received those of saline $(8 \mathrm{ml} / \mathrm{kg})$. The observation of the death of the animals was made for $44 \mathrm{~d}$. In a separate experiment, 2 animals were randomly taken from each group at $16 \mathrm{~d}$ after challenge, and lung, liver, spleen and kidneys were examined

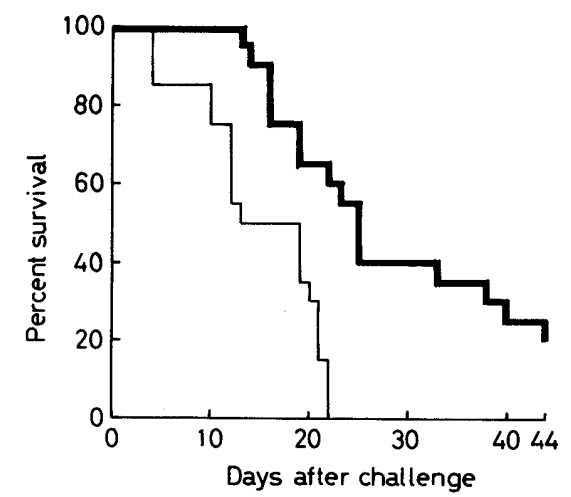

Fig. 1. Effect of FA on the Survival Time of Mice with Candidiasis

Groups of 20 mice were challenged with Candida albicans. They were treated $1 \mathrm{~d}$ after challenge with daily intraperitoneal injections of saline $(8 \mathrm{ml} / \mathrm{kg})$ or FA $(40 \mathrm{mg} / \mathrm{kg})$. The survival rate (percent survival) is indicated by a solid line for the saline-injected control group and by a bald line for the FA-injected group. histologically. Tissue samples for microscopic examination were fixed in $10 \%$ formaline, embedded in paraffin, sectioned, and stained with hematoxylin and eosin.

\section{Results and Discussion}

Figure 1 shows the effect of FA on the survival of mice after being challenged with Candida albicans. A total of 40 animals, 20 animals per group, were used for the experiment. All animals of the control group injected with saline were dead within $22 \mathrm{~d}$ after challenge. The injections of FA delayed the death of animals and prevented 4 animals $(20 \%$ of a total of 20 animals) from dying of fungal infection after $44 \mathrm{~d}$.

Histological examination was made on the animals killed at $16 \mathrm{~d}$ after challenge. Responses of the tissues to the fungal infection were noted in the animals of the control group; presence of secretions and focal bleeding in the bronchi of the lung (Fig. 2a), infiltration of neutrophils in the liver and kidneys (Figs. 2b and c), and a marked development of immature lymphoblasts in the white pulp of the spleen (Fig. $2 \mathrm{~d}$ ). In contrast, no such pathological responses were noted in the tissues of the animals of the FA-treated group except a slight development of immature lymphoblasts in the white pulp of the spleen (Figs. $2 \mathrm{e}-\mathrm{h}$ ).

The presnet findings indicate that FA effectively retarded the development of systemic candidiasis. There are a few clinically useful drugs for systemic mycoses. The classical and representative examples are amphotericin B, 5fluorocytocin and ketokonazol. ${ }^{9}$ However, each one has its limitation, e.g., side effects, risk of resistance, or poor penetration into certain components of the body. ${ }^{9)} \mathrm{FA}$ is a simple dicarboxylic acid and is expected to have a low toxicity in chemotherapeutic use. FA has the ability to reduce toxic symptoms in mice and rats injected with mitomycin $\mathrm{C}$ and aflatoxin $\mathrm{B}_{1},{ }^{3-5)}$ and is expected to be useful for the combination therapy.

References

1) K. Kuroda, M. Akao, M. Kanisawa and K. Miyaki, Cancer Res., 36, 1900 (1976).

2) K. Kuroda and M. Akao, Arch. Int. Pharmacodyn. Ther., 226, 324 (1977).

3) K. Kuroda and M. Akao, Biochem. Phamacol., 29, 2839 (1980).

4) K. Kuroda, S. Teranishi and M. Akao, Gann, 73, 656 (1982).

5) K. Kuroda and M. Akao, Jpn.J. Cancer Res. (Gann), 77, 750 (1986).

6) K. Kuroda, T. Terao and M. Akao, J. Natl. Cancer Inst., 71, 855 (1983).

7) K. Kuroda, K. Terao and M. Akao, J. Natl. Cancer Inst., 79, 1047 (1987).

8) M. Akao and K. Kuroda, Chem. Pharm. Bull., 38, 2012 (1990).

9) A. Polak, H. S. Scholer and M. Wall, Chemotherapy, 28, 461 (1982). 

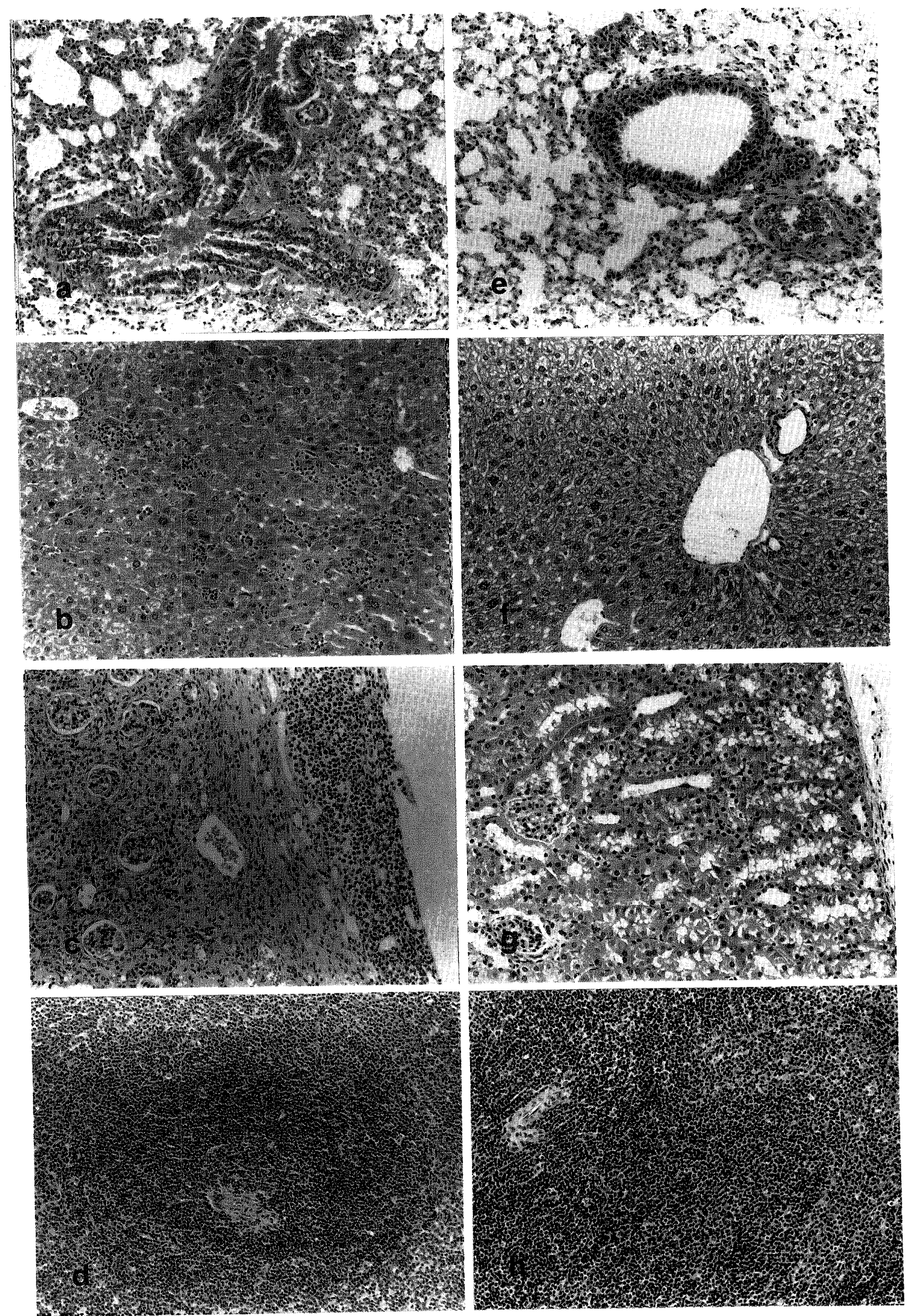

Fig. 2. Micrographs of the Tissues of Mouse Treated with Daily Injections of Saline or FA for $16 \mathrm{~d}$ after Challenge with Candida albicans

Figures 2a-d are micrographs of the tissues for the saline-injected control mouse. $\times 100$. a) Lung; secretions and focal bleeding are seen in the bronchus. b) Liver: Figute infiltration of neutrophils into the sinusoids. c) Kidney; infiltration of neutrophils into the fibrous membrane of the capsule. findings. h) Spleen; a slight development of lymphoblasts in the white pulp. 